\title{
Medicaid Patients in Dental School Clinics: Do Personal and Professional Experiences Matter?
}

\begin{abstract}
Anthony Edward Valentine, D.D.S.; Marita R. Inglehart, Dr. phil. habil.
Abstract: The purpose of this study was to explore dental and dental hygiene students' and faculty members' personal experiences with Medicaid prior to coming to dental school as well as their professional/educational experiences with patients on Medicaid during their dental/dental hygiene education and how these experiences relate to their professional attitudes and behavior concerning treating patients on Medicaid. Survey data were collected from 317 dental students, fifty-five dental hygiene students, and fifty-seven clinical faculty members at the University of Michigan. The results showed that while responding students' confidence concerning treating Medicaid patients increased over the course of their education, their intention to treat these patients actually decreased. The more personal experiences with Medicaid these students had before dental school, the more they enjoyed treating Medicaid patients, the more confident they were when treating these patients, and the more likely they were to treat these patients in the future. The more professional experiences these students had during dental school, the more they enjoyed treating Medicaid patients, and the more confident they were when treating these patients, but the less likely they were to treat them in the future. In conclusion, experiences with Medicaid before dental school as well as professional experiences during dental education correlated with later professional attitudes and behaviors. The implications of these findings for dental education are explored.
\end{abstract}

Dr. Valentine is a graduate student in the AEGD Program, School of Dentistry, University of Michigan; and Dr. Inglehart is Associate Professor, Department of Periodontics and Oral Medicine, School of Dentistry, University of Michigan. Direct correspondence and requests for reprints to Dr. Marita R. Inglehart, Department of Periodontics and Oral Medicine, School of Dentistry, University of Michigan, 1011 North University Avenue, Ann Arbor, MI 48109-1078; 734-763-8073 phone; 734-763-5503 fax; mri@umich.edu.

Keywords: Medicaid, access to care, dental education, dental hygiene education, professional attitudes, oral health, dental students, dental hygiene students, dental faculty

Submitted for publication 4/24/10; accepted 7/1/10

$\mathrm{M}$ edicaid is a joint federal and state government-run program found in Titles XVIII and XIX of the Social Security Act, which pays specific health care costs for eligible, lowincome individuals. ${ }^{1}$ The Medicaid service is the largest source of funding for health-related services for America's poorest citizens. Its programs allow patients who normally would be unable to afford health care the ability to acquire medical and dental benefits as long as they satisfy certain requirements. Both the Medicaid and Medicare programs were signed into law by President Lyndon Johnson on July 30, 1965. ${ }^{2}$ Each state follows federal guidelines but establishes its own Medicaid program - thus controlling eligibility, length, and rate of payment for all services and the degree to which dental coverage is provided. However, even if a pediatric or adult patient is covered by Medicaid, this patient can encounter problems when trying to utilize dental services because not all dental providers accept patients with Medicaid coverage. For example, in 2007, only about 26.7 percent of dentists who participated in a survey administered by the American Dental Association
(ADA) reported that they treated Medicaid patients. ${ }^{3}$ The U.S. surgeon general's report on oral health was therefore quite correct when pointing out that eligibility for Medicaid does not ensure enrollment and that being enrolled in Medicaid does not ensure that patients have access to needed care. ${ }^{4}$

Dental care providers give several reasons why they choose not to accept Medicaid, with the most common involving reimbursement rates and practice management issues. For example, in 2007, the ADA president stated that reimbursement rates were low and often did not cover dentists' overhead, which discourages dentists from participating in the Medicaid program. ${ }^{5}$ In another study, orthodontists who were current Medicaid providers, past Medicaid providers, or who had never participated in the program all agreed that low reimbursement fees were a major problem. ${ }^{6}$ Increasing fees can therefore have a positive effect on the percentage of dentists who accept patients on Medicaid, as a recent study in Indiana showed. ${ }^{7}$ After the fees were increased and changes in the administration of the Indiana Dental Medicaid program were made, dentist participation 
in the Medicaid program improved, and children's use of dental services increased.

A second financial concern is related to Medicaid reimbursement not happening in a timely fashion. The Academy of General Dentistry pointed out in 2007 that only ten of the fifty states in the United States allow for direct Medicaid reimbursement for dental hygienists. ${ }^{8}$ Aside from financial concerns, practice management-related issues such as higher percentages of missed or cancelled appointments by Medicaid patients and frustration with the Medicaid system itself are cited by providers as additional reasons for not accepting patients covered by Medicaid. Researchers have found, for example, that pediatric dental patients on Medicaid had higher appointment failure rates, cancellations, and tardiness than nonMedicaid patients. ${ }^{9}$ In consideration of these reasons for nonparticipation, it is also crucial to understand that the number of dental providers who accept patients on Medicaid is even declining in some states. For example, a report by the Utah Medical Education Council showed in 2006 that approximately 73.3 percent of Utah dentists would not accept new Medicaid patients due to the low Medicaid reimbursement and the high frequency of missed appointments by Medicaid patients. ${ }^{10}$ Furthermore, according to this report, only 23.9 percent of Utah dentists provided services to Medicaid patients. An important question therefore is how the number of dental care providers who accept patients on Medicaid can be increased and which factors might play a role in this context. Our study explored two factors: the role of students' personal experiences with Medicaid prior to coming to dental school and the role of professional/educational experiences during dental school.

It might be worthwhile to explore how personal background factors - such as the students' and faculty members' own experiences with Medicaid and their prior knowledge about Medicaid - affect their later professional responses. Research has found, for example, that health care providers from underrepresented minority groups were more likely than their European American colleagues to serve minority and medically underserved communities. ${ }^{11-18}$ This finding could potentially be interpreted as being related to an increased level of comfort when providing care to these patients due to prior interactions with these populations. In addition, this trend can already be found when analyzing the data from senior dental student surveys. Weaver et al. reported, for example, in their analyses of data from the 2002 survey that approximately 69 percent of black/African American,
45 percent of Hispanic/Latino, and 35 percent of Asian/Pacific Islander seniors planned to provide care for underserved populations after graduation, while only 20 percent of the white seniors intended to do so. ${ }^{19}$ Our study therefore explored whether certain personal experiences prior to entering dental school might affect students' and faculty members' attitudes and behavior concerning treating patients on Medicaid given that the dental educational experiences were shared by all students. Objective 1 of this study thus focused on analyzing how knowledge and personal experiences with Medicaid before coming to dental school would affect the respondents' confidence and attitudes when treating patients on Medicaid as well as their willingness to do so.

In addition to exploring the importance of personal experiences and knowledge prior to coming to dental school, this study also investigated the role of professional/educational factors in this context. Research has found that the quality of predoctoral dental education about providing care for underserved patients affected future providers' willingness to treat underserved patients such as patients with special health care needs, ${ }^{20}$ children, ${ }^{21}$ and patients from underrepresented minority and/or low-income groups. ${ }^{22}$ In addition, research with dental specialists has found that graduate educational experiences in orthodontics and in periodontics also affected these specialists' willingness to treat underserved patients as well as their attitudes towards these patient groups..$^{23,24}$ These studies documented that dental education has a clear effect on students' and dentists' attitudes and professional behavior. In addition, research has found that certain types of educational experiences such as community-based clinical rotations were especially valuable in this context. ${ }^{25}$ One could therefore argue that actual experiences in the clinical setting that are closely related to the future professional clinical work of the students will be of particular interest in this context. Objective 2 of our study therefore focused on analyzing how clinical/ professional/educational experiences with Medicaid patients might affect students' and faculty members' confidence and attitudes concerning treating these patients and their willingness to do so.

\section{Methods}

This research was approved by the Institutional Review Board for the Health Sciences (IRB-Health) at the University of Michigan (\# HUM00027430). 
Data were collected from 317 dental students (response rate: 73 percent), fifty-five dental hygiene students (response rate: 63 percent), and fifty-seven faculty members. Dental students were equally distributed between male ( 51 percent) and female (49 percent) students, while most dental hygiene students were female ( 98 percent) and about two-thirds of the faculty members were male ( 63 percent). The majority of respondents in each of the three groups were European American (dental students: 68 percent; dental hygiene: 85 percent; faculty: 78 percent), with Asian American respondents being the second most frequently named ethnicity/race (18 percent, 4 percent, 12 percent).

Concerning the response rates, it is important to realize that 100 percent of the first-year dental students, 65 percent of the second- and third-year students, and 64 percent of the fourth-year students volunteered to participate in this study. The fact that fewer upper-class students responded is partly due to their engagement in activities such as external or hospital rotations and their resulting lower class attendance in these academic years. For example, about 10 percent of the junior dental students are on dental school clinic or hospital rotations on any given day, and about 20 to 30 percent of the senior dental students are participating in communitybased dental clinic rotations at any given time. It is therefore likely that some students were not in the classrooms when the surveys were handed out and thus did not participate in this study. A similar situation was encountered when distributing surveys in dental hygiene classes. Nearly all the students present responded positively to the recruitment message and returned the surveys. However, quite a number of dental hygiene students were not in class for one reason or another. It is not possible to determine a definitive response rate for the faculty members because the recruitment letter to the survey placed in faculty mailboxes asked them to only respond if the faculty member worked in the clinics with students. However, the percentages of male and female respondents in the three groups and of European American respondents versus respondents from other ethnic/racial groups mirrored the actual percentages of dental and dental hygiene students and faculty members in the dental school.

The dental and dental hygiene students were informed about the study at the beginning or end of a regularly scheduled class. If they volunteered to respond, they did so right away and then returned the questionnaire anonymously in a sealed envelope to the researchers to protect their privacy. The faculty members received the survey in their departmental mail boxes with a cover letter that explained the study and an addressed campus mail return envelope. They were told that only clinical faculty and not basic science or research faculty should respond to the survey.

About five months before this survey was distributed, a pilot survey with only a few questions about Medicaid was conducted with third-year dental students. Based on these findings, the more comprehensive survey was developed, and the data were collected in March and April 2009. The survey consisted of two pages copied back to back. On the first page, respondents were asked to provide demographic information (gender, age, ethnicity/race, and year of educational experience) and to respond to six questions concerning their educational experiences with Medicaid in the dental school. These questions asked whether they had worked with patients on Medicaid in the dental school clinics before, how much experience they had with working with patients on Medicaid, how many patients on Medicaid they had in their patient family, whether they had encountered challenges/problems with Medicaid patients, and how severe these problems had been. In addition, they were asked to indicate how confident they were when treating patients on Medicaid and when answering patients' questions about Medicaid and how much they enjoyed working with patients on Medicaid. The questions on the second page focused on their future plans and their experiences before coming to dental school. Concerning their future plans, the respondents indicated how likely they were to treat patients on Medicaid in the future in a private practice setting, whether they would accept all patients on Medicaid or only Medicaid patients with certain characteristics, and how many Medicaid patients they would accept. Concerning their experiences with Medicaid prior to coming to the dental school, they were asked how their own families had paid for dental services while the student was growing up, how much they knew about Medicaid, how many experiences they had with Medicaid before coming to dental school, and whether any of their family members, friends, acquaintances, or persons in a work-related setting had been on Medicaid. The final question asked whether they would like to learn more about Medicaid.

The data were analyzed with SPSS, Version 17. Descriptive statistics (percentages, frequency 
distributions, means, standard deviations, and ranges) were computed to describe the data. Univariate analyses of variance were computed to test whether the three groups of respondents (dental students, dental hygiene students, and faculty members) as well as students in different years of their program (four years for dental students; three years for dental hygiene students) differed in their average responses to the rating scale questions. Chi-square tests were used to determine whether the frequencies of responses concerning the categorical questions differed as a function of the type of respondent and of the year of program attended. Pearson correlation coefficients were computed to explore the relationships between the variables studied.

\section{Results}

Table 1 provides an overview of personal and professional experiences of respondents before they came to the dental school. Concerning personal experiences, the first question asked respondents how their families paid for dental treatment while the student was growing up. The percentages of dental students, dental hygiene students, and faculty members whose families had dental insurance differed significantly. Dental hygiene students had the highest percentage ( 84 percent) and faculty members had the lowest percentage ( 30 percent) of respondents whose families had dental insurance. The three groups also differed significantly in the percentage of respon-

Table 1. Respondents' experiences with Medicaid before coming to dental school

\begin{tabular}{|c|c|c|c|c|}
\hline & \multicolumn{2}{|r|}{ Students } & \multirow[b]{2}{*}{ Faculty } & \multirow[b]{2}{*}{$\mathrm{p}$} \\
\hline & Dental & Dental Hygiene & & \\
\hline \multicolumn{5}{|l|}{ Personal Experiences } \\
\hline $\begin{array}{l}\text { How did your family pay for dental treatment when you were growing up? } \\
\text { Dental insurance } \\
\text { Paid privately } \\
\text { Medicaid } \\
\text { Dentist in family } \\
\text { Other }\end{array}$ & $\begin{array}{l}64 \% \\
46 \% \\
2 \% \\
7 \% \\
1 \%\end{array}$ & $\begin{array}{l}84 \% \\
24 \% \\
4 \% \\
2 \% \\
4 \%\end{array}$ & $\begin{array}{l}30 \% \\
75 \% \\
0 \\
0 \\
4 \%\end{array}$ & $\begin{array}{l}<0.001 \\
<0.001\end{array}$ \\
\hline $\begin{array}{l}\text { How would you describe your own family's socioeconomic status? } \\
\text { Lower socioeconomic level } \\
\text { Middle class } \\
\text { Upper middle class } \\
\text { Upper class }\end{array}$ & $\begin{array}{c}6 \% \\
43 \% \\
45 \% \\
9 \%\end{array}$ & $\begin{array}{c}6 \% \\
78 \% \\
16 \% \\
2 \%\end{array}$ & $\begin{array}{c}9 \% \\
65 \% \\
25 \% \\
5 \%\end{array}$ & $<0.001$ \\
\hline How much did you know about Medicaid before dental school? & 1.90 & 2.13 & 1.81 & 0.245 \\
\hline How much experience did you have with Medicaid before dental school?² & 1.54 & 1.89 & 1.47 & 0.042 \\
\hline $\begin{array}{l}\text { Before you came to the } U \text { of } M \text {, did you have any contacts with Medicaid for } \\
\text { yourself } \\
\text { family members } \\
\text { friends } \\
\text { acquaintances } \\
\text { persons at work }\end{array}$ & $\begin{array}{c}0 \\
17 \% \\
16 \% \\
22 \% \\
2 \%\end{array}$ & $\begin{array}{c}2 \% \\
18 \% \\
24 \% \\
29 \% \\
2 \%\end{array}$ & $\begin{array}{c}2 \% \\
16 \% \\
11 \% \\
20 \% \\
0\end{array}$ & $\begin{array}{c}-\overline{8} \\
0.146 \\
0.354 \\
-\end{array}$ \\
\hline \multicolumn{5}{|l|}{ Professional Experiences } \\
\hline Have you ever worked with Medicaid patients in a dental clinic? Yes & $71 \%$ & $73 \%$ & $81 \%$ & 0.303 \\
\hline How experienced are you with working with patients on Medicaid? ${ }^{3}$ & 2.90 & 3.16 & 3.96 & $<0.001$ \\
\hline How many patients in your patient population are on Medicaid? & 11.97 & 11.60 & 28.22 & 0.006 \\
\hline Have you experienced any problems with providing care for patients on Medicaid? & $\begin{array}{l}\text { Yes: } \\
51 \%\end{array}$ & $\begin{array}{l}\text { Yes: } \\
22 \%\end{array}$ & $\begin{array}{l}\text { Yes: } \\
74 \%\end{array}$ & $<0.001$ \\
\hline How severe were the problems you encountered with Medicaid patients & 2.69 & 2.39 & 3.32 & $<0.001$ \\
\hline
\end{tabular}

${ }^{1}$ Answers ranged from $1=$ nothing to $5=$ very much.

${ }^{2}$ Answers ranged from $1=$ no experience at all to $5=$ very much.

${ }^{3}$ Answers ranged from $1=$ not at all experienced to $5=$ very experienced.

${ }^{4}$ Answers ranged from $1=$ not at all severe to $5=$ extremely severe.

Note: Under Personal Experiences, questions 1 and 5 asked respondents to select all that applied; percentages of respondents to question 2 do not total $100 \%$ because of rounding. 
dents who paid privately for dental treatment, with faculty members having the highest percentage (75 percent) and dental hygiene students having the lowest percentage ( 24 percent). It has to be noted that the respondents could give more than one answer to this survey question, so the percentages can total over 100 percent. Only six dental students and two dental hygiene students had been covered by Medicaid while they were growing up. When the respondents were asked to describe their parents' socioeconomic status, the majority of respondents indicated that they were from a middle class or upper middle class background (dental students: 88 percent; dental hygiene students: 94 percent; faculty: 90 percent). Only a small percentage from each of the three groups indicated that they were from a lower socioeconomic background (dental students: 6 percent; dental hygiene students: 6 percent; faculty: 9 percent).

The answers to the question how much the respondents knew about Medicaid prior to dental school were given on a five-point answer scale ranging from $1=$ nothing to $5=$ very much. All respondents in the three groups indicated that they, on average, knew very little about Medicaid before coming to dental school (dental students: 1.90; dental hygiene students: 2.13; faculty: 1.81) and that they had very little experience with Medicaid prior to coming to dental school $(1.54 ; 1.89 ; 1.47)$. When asked if they had any contacts with Medicaid for themselves, family members, friends, acquaintances, or persons at work, 16 to 18 percent reported having had experiences with family members, 11 to 24 percent reported experiences with friends, and 20 to 29 percent reported experiences with acquaintances (Table 1). In summary, these data showed that prior experiences with persons on Medicaid were limited to a small segment of the respondents.

Concerning the respondents' professional experiences with Medicaid, most of the respondents (between 71 and 81 percent) indicated that they had worked with patients on Medicaid in dental clinics (Table 1). However, the dental and dental hygiene students only reported on average a medium level of experience with working with patients on Medicaid, while the faculty indicated a higher level of experience working with this patient population (on a fivepoint scale with $1=$ not at all experienced and $5=$ very experienced, dental students averaged 2.90, dental hygiene students 3.16 , and faculty $3.96 ; \mathrm{p}<0.001$ ). On average, the students averaged eleven to twelve patients on Medicaid in their patient population, while faculty members reported a significantly higher number of twenty-eight patients being currently in their patient families.

When the respondents were asked if they had ever experienced any problems or challenges working with Medicaid patients, 51 percent of dental students, 22 percent of dental hygiene students, and 74 percent of faculty members reported experiencing problems or challenges. The responses to an open-ended follow-up question concerning which type of problems the respondents had encountered showed that responses concerning the financial side of Medicaid (examples: "no good coverage" or "Medicaid not paying for needed treatment") were most frequently mentioned (dental students: 71 percent; dental hygiene students: 89 percent; faculty: 68 percent). For the dental students, bureaucratic reasons such as "paperwork," "billing," and "waiting for prior authorization" followed as a second most-cited problem, while this was no issue for dental hygiene students whose services were covered by Medicaid. Only 13 percent of the faculty members named this problem. However, 55 percent of the faculty members cited patient factors such as "don't value care" and "noncompliance" as a challenge, followed by 35 percent of the dental students and 16 percent of the dental hygiene students. Finally, missed or cancelled appointments were cited as a challenge by 27 percent of the dental students, 5 percent of the dental hygiene students, and 30 percent of the faculty members. Concerning the question of how severe these problems had been, the respondents indicated that these problems were on average at a medium degree of severity (dental students 2.69 , dental hygiene students 2.39 , faculty $3.32, p<0.001$ ), with faculty members having encountered the most severe problems.

An overview of responses concerning respondents' professional attitudes and behavioral intentions about treating Medicaid patients is provided in Table 2. On average, the dental and dental hygiene students had a medium degree of confidence when treating patients on Medicaid, while the dental faculty members' confidence was high (dental students 3.47, dental hygiene students 3.78 , faculty $4.53 ; \mathrm{p}<0.001$ ). However, when we analyzed the average responses concerning how confident the respondents were when answering questions about Medicaid, the data showed that both the dental and dental hygiene students had a rather lower level of confidence (dental students 2.55, dental hygiene students 2.18) and even faculty members were not as confident (3.27). The final attitudinal 
Table 2. Respondents' professional attitudes and behavioral intentions concerning providing care for patients on Medicaid

\begin{tabular}{|c|c|c|c|c|}
\hline & \multicolumn{2}{|c|}{ Students } & \multirow[b]{2}{*}{ Faculty } & \multirow[b]{2}{*}{$\mathrm{p}$} \\
\hline & Dental & $\begin{array}{l}\text { Dental } \\
\text { Hygiene }\end{array}$ & & \\
\hline \multicolumn{5}{|l|}{ Professional Attitudes } \\
\hline \multicolumn{5}{|l|}{ How confident are you when you ... } \\
\hline $\begin{array}{l}\text { treat patients on Medicaid?' } \\
\text { answer patient questions about Medicaid? }\end{array}$ & $\begin{array}{l}3.47 \\
2.55\end{array}$ & $\begin{array}{l}3.78 \\
2.18\end{array}$ & $\begin{array}{l}4.53 \\
3.27\end{array}$ & $\begin{array}{l}<0.001 \\
<0.001\end{array}$ \\
\hline How much do you enjoy working with patients on Medicaid? ${ }^{2}$ & 3.21 & 3.65 & 3.54 & 0.006 \\
\hline \multicolumn{5}{|l|}{ Professional Behavior } \\
\hline How likely are you to treat patients on Medicaid in the future in private practice? $?^{3}$ & 2.85 & 3.29 & 2.30 & $<0.001$ \\
\hline Would you accept only certain groups of Medicaid patients? & $\begin{array}{l}\text { Yes: } \\
55 \%\end{array}$ & $\begin{array}{l}\text { Yes: } \\
22 \%\end{array}$ & $\begin{array}{l}\text { Yes: } \\
33 \%\end{array}$ & $<0.001$ \\
\hline Would you accept only a limited number of Medicaid patients? & $\begin{array}{l}\text { Yes: } \\
80 \%\end{array}$ & $\begin{array}{l}\text { Yes: } \\
32 \%\end{array}$ & $\begin{array}{l}\text { Yes: } \\
66 \%\end{array}$ & $<0.001$ \\
\hline $\begin{array}{l}{ }^{1} \text { Answers ranged from } 1=\text { not at all to } 5=\text { completely confident. } \\
{ }^{2} \text { Answers ranged from } 1=\text { not at all to } 5=\text { very much. } \\
{ }^{3} \text { Answers ranged from } 1=\text { not at all likely to } 5=\text { extremely likely. }\end{array}$ & & & & \\
\hline
\end{tabular}

question asked how much the respondents enjoyed working with patients on Medicaid. The data showed that the dental students had the least positive response (3.21), with the dental hygiene students having the most enjoyment (3.65) and the faculty members having an intermediate degree $(3.54 ; \mathrm{p}=0.006)$.

Concerning the respondents' behavioral intentions related to providing care for patients on Medicaid (Table 2), responding dental students did not think they were very likely to treat patients on Medicaid in the future (2.85), and the dental hygiene students were only slightly more positive (3.29). Faculty members were least positive (2.30; $\mathrm{p}<0.001)$. When asked whether they would be willing to accept all types of patients on Medicaid or only specific groups of Medicaid patients (such as family members of patients who were insured or patients on Medicaid who had been previously insured patients), 55 percent of dental students, 22 percent of dental hygiene students, and 33 percent of faculty members answered they would treat only certain groups of Medicaid patients. In addition, when asked if they would accept all or only a limited number of Medicaid patients, 80 percent of the dental students, 66 percent of the faculty members, and 32 percent of the dental hygiene students responded that they would treat only a limited number of Medicaid patients.

One interesting question is whether dental and dental hygiene students change their professional attitudes and behavioral intentions over the course of their educational experiences. Table 3 shows that the confidence of both the responding dental and dental hygiene students concerning providing care for patients on Medicaid and answering questions about Medicaid increased significantly over the course of their educational experience. However, the responses to the question of how much the students enjoyed working with patients on Medicaid showed that while ultimately both groups of students reported the highest level of enjoyment in their last year of education, the third-year dental students had a lower level of enjoyment. While their confidence level increased, the dental students' intentions to provide care for patients on Medicaid in the future decreased from the first year to a low average response of 2.57 in the fourth year. However, the percentages of students who indicated that they would accept only certain types of Medicaid patients and/or only a limited number of Medicaid patients did not differ significantly from the dental and dental hygiene cohorts.

The first objective of this study was to analyze whether personal experiences prior to starting dental or dental hygiene education were correlated with professional attitudes and behavior concerning patients on Medicaid. Table 4 shows that the more knowledge and experience the respondents had before their professional training, the more confident they were in treating patients on Medicaid and answering questions about Medicaid, the more they enjoyed treating 
Table 3. Responding students' professional attitudes and behavioral intentions concerning Medicaid patients in the different program years

Dental Students Dental Hygiene Students

\begin{tabular}{|c|c|c|c|c|c|c|c|}
\hline & D1 & D2 & D3 & D4 & $\mathrm{DH} 2$ & $\mathrm{DH} 3$ & $\mathrm{DH} 4$ \\
\hline \multicolumn{8}{|l|}{ Professional Attitudes } \\
\hline \multicolumn{8}{|l|}{ How confident are you when you . . . } \\
\hline treat patients on Medicaid?'1 & 2.69 & 3.03 & 3.93 & $4.29 * * *$ & 3.44 & 3.17 & $4.45^{* *}$ \\
\hline answer patient questions about Medicaid?'1 & 2.12 & 1.91 & 2.82 & $3.39 * * *$ & 2.28 & 1.31 & $2.65^{* *}$ \\
\hline $\begin{array}{l}\text { How much do you enjoy working with patients } \\
\text { on Medicaid?? }\end{array}$ & 3.27 & 3.26 & 2.81 & $3.54^{* * *}$ & 3.36 & 3.39 & 4.00 \\
\hline \multicolumn{8}{|l|}{ Professional Behavior } \\
\hline $\begin{array}{l}\text { How likely are you to treat patients on Medicaid } \\
\text { in the future in private practice? } ?^{3}\end{array}$ & 3.47 & 3.04 & 2.12 & $2.57^{* * *}$ & 3.28 & 3.42 & 3.24 \\
\hline $\begin{array}{l}\text { Would you accept only certain groups of } \\
\text { Medicaid patients? }\end{array}$ & $\begin{array}{l}\text { Yes: } \\
54 \%\end{array}$ & $\begin{array}{l}\text { Yes: } \\
54 \%\end{array}$ & $\begin{array}{l}\text { Yes: } \\
60 \%\end{array}$ & $\begin{array}{l}\text { Yes: } \\
52 \%\end{array}$ & $\begin{array}{l}\text { Yes: } \\
29 \%\end{array}$ & $\begin{array}{l}\text { Yes: } \\
8 \%\end{array}$ & $\begin{array}{l}\text { Yes: } \\
24 \%\end{array}$ \\
\hline $\begin{array}{l}\text { Would you accept only a limited number of } \\
\text { Medicaid patients? }\end{array}$ & $\begin{array}{l}\text { Yes: } \\
78 \%\end{array}$ & $\begin{array}{l}\text { Yes: } \\
73 \%\end{array}$ & $\begin{array}{l}\text { Yes: } \\
90 \%\end{array}$ & $\begin{array}{l}\text { Yes: } \\
79 \%\end{array}$ & $\begin{array}{l}\text { Yes: } \\
50 \%\end{array}$ & $\begin{array}{l}\text { Yes: } \\
18 \%\end{array}$ & $\begin{array}{l}\text { Yes: } \\
25 \%\end{array}$ \\
\hline \multicolumn{8}{|c|}{$\begin{array}{l}{ }^{1} \text { Answers ranged from } 1=\text { not at all to } 5=\text { completely confident. } \\
{ }^{2} \text { Answers ranged from } 1=\text { not at all to } 5=\text { very much. } \\
{ }^{3} \text { Answers ranged from } 1=\text { not at all likely to } 5=\text { extremely likely. }\end{array}$} \\
\hline \multicolumn{8}{|l|}{$* * \mathrm{p}<0.01 ; * * * \mathrm{p} \leq 0.001$} \\
\hline
\end{tabular}

Table 4. Correlations between respondents' experiences before dental education and their professional attitudes and behavioral intentions

\begin{tabular}{|c|c|c|c|c|c|c|}
\hline & \multicolumn{3}{|c|}{ Attitudes } & \multicolumn{3}{|c|}{ Behavioral Intentions to Treat } \\
\hline & $\begin{array}{l}\text { Confident } \\
\text { to Treat }\end{array}$ & $\begin{array}{l}\text { Confident } \\
\text { to Answer } \\
\text { Questions }\end{array}$ & Enjoy ${ }^{6}$ & $\begin{array}{l}\text { Likely } \\
\text { to Treat }\end{array}$ & $\begin{array}{l}\text { All or } \\
\text { Specific } \\
\text { Patients }\end{array}$ & $\begin{array}{c}\text { All or } \\
\text { Limited } \\
\text { Number } \\
\text { of Patients }\end{array}$ \\
\hline \multicolumn{7}{|c|}{ Personal Experience Before Dental Education } \\
\hline Medicaid knowledge ${ }^{1}$ & $.10^{*}$ & $.12^{*}$ & $.20 * * *$ & $.17 * * *$ & .14 & $.17^{*}$ \\
\hline Medicaid experience ${ }^{2}$ & $.086^{+}$ & $.13 * *$ & $.19 * * *$ & $.17^{* * *}$ & .08 & .10 \\
\hline Number of persons on Medicaid known & .022 & .042 & $.12^{*}$ & $.17 * * *$ & $.13+$ & $.17^{*}$ \\
\hline Socioeconomic background & $-.11 *$ & -.070 & $-.13 *$ & $-.09+$ & .095 & $.15^{*}$ \\
\hline \multicolumn{7}{|l|}{ Professional Experiences } \\
\hline Experience with Medicaid patients ${ }^{3}$ & $.62 * * *$ & $.52 * * *$ & $.17^{* *}$ & $-.19 * * *$ & .068 & .037 \\
\hline $\begin{array}{l}\text { Number of Medicaid patients in patient } \\
\text { population }\end{array}$ & $.29 * * *$ & $.26 * * *$ & .118 & $-.19 * *$ & .326 & .392 \\
\hline Problems yes/no & $.33^{* * *}$ & $.33 * * *$ & $.21^{* *}$ & $.31 * * *$ & $.13^{*}$ & $.17^{* *}$ \\
\hline Severity of problems ${ }^{4}$ & $.18^{* *}$ & $.19 * * *$ & $-.21 * * *$ & $-.24 * * *$ & $.25 * * *$ & .17 \\
\hline \multicolumn{7}{|c|}{$\begin{array}{l}{ }^{1} \text { Answers ranged from } 1=\text { nothing to } 5=\text { very much. } \\
{ }^{2} \text { Answers ranged from } 1=\text { no experience at all to } 5=\text { very much. } \\
{ }^{3} \text { Answers ranged from } 1=\text { not at all experienced to } 5=\text { very experienced. } \\
{ }^{4} \text { Answers ranged from } 1=\text { not at all severe to } 5=\text { extremely severe. } \\
{ }^{5} \text { Answers ranged from } 1=\text { not at all to } 5=\text { completely confident. } \\
{ }^{6} \text { Answers ranged from } 1=\text { not at all to } 5=\text { very much. } \\
7{ }^{7} \text { Answers ranged from } 1=\text { not at all likely to } 5=\text { extremely likely. }\end{array}$} \\
\hline${ }^{+} p \leq 0.10 ;{ }^{*} p \leq 0.05 ;{ }^{* *} p<0.01 ; * * * p \leq 0.001$ & & & & & & \\
\hline
\end{tabular}

these patients, and the more likely they were to intend to treat these patients in the future. In addition, the more persons on Medicaid they had known, the more they enjoyed working with these patients and the more likely they were to treat them in the future. As predicted, the lower the respondents' family so- 
cioeconomic status had been, the more they enjoyed working with these patients and the more likely they were to provide care in the future and to indicate that they would not limit the number of Medicaid patients they would treat.

The same pattern of results holds when analyzing the attitudinal findings concerning the second objective, which focuses on the relationships between respondents' professional experiences and these attitudes and behavioral intentions. The more experienced the students were with Medicaid patients and the more Medicaid patients they had in their patient populations, the more confident they were both treating these patients and answering questions about Medicaid and the more they enjoyed working with Medicaid patients. However, negative correlations were found between these professional experiences and the respondents' behavioral intentions: the more experiences they had and the more patients on Medicaid they included in their patient families, the less likely they were to indicate that they would treat these patients in the future.

Having encountered problems with Medicaid patients had a significant relationship with the respondents' confidence level, enjoyment, and behavioral intentions. However, the more severe these problems had been, the more confident the respondents had been, but the less they enjoyed their interactions and were likely to intend to treat these patients in the future.

In addition to exploring the relationship between personal and professional experiences and attitudes and behavior, it may also be worthwhile to explore whether respondents from different demographic groups had different personal experiences prior to their professional training and differed in their professional attitudes and professional behavior concerning treating patients on Medicaid. Concerning differences between responses of the male and female subjects, there was a tendency for female respondents to have had a higher knowledge and more experiences with Medicaid and that they enjoyed working with these patients more, would be more likely to treat them in the future, and less likely to restrict the types and number of Medicaid patients they would treat compared to their male colleagues (Table 5). Also, non-white respondents seemed to be more confident than white respondents in answering questions about Medicaid and in their intentions to treat more patients on Medicaid. Finally, respondents from a lower socioeconomic family background had more experiences with Medicaid before their training and enjoyed working with Medicaid patients more but were not more likely to treat patients on Medicaid than respondents from higher socioeconomic backgrounds.

\section{Discussion}

Before we discuss these findings, it is interesting to note that severe cuts to the dental coverage of Medicaid patients in the state of Michigan have been made since the data for this study were collected in the spring of $2009 .{ }^{26}$ This situation changes the experiences of dental and dental hygiene students because it limits the type of dental procedures covered by Medicaid for adult patients to emergency treatment. As a result, the students who entered the clinical phase of their dental and dental hygiene education since June 2009 have far fewer experiences with Medicaid compared to the students who responded to this survey before the cuts were announced. Future research should therefore explore how these changes will affect the professional experiences and, as a consequence, the attitudes and behavior of these students.

Concerning students' personal experiences with Medicaid prior to attending dental school or the dental hygiene program, the data showed that very few of the respondents had ever been covered by Medicaid themselves or were from a lower socioeconomic family background. Small percentages of students ever knew a family member, friend, or acquaintance on Medicaid. It is therefore not surprising that these respondents had relatively low levels of knowledge and experience with Medicaid. Given this situation, it is crucial to educate students about Medicaid and its dental coverage once they enter professional training and especially the clinical phase of their programs. It would therefore be worthwhile in future research to analyze how various dental schools and dental hygiene programs introduce this topic and cover it in their curricula, in order to gain a better understanding of ways to optimally inform students about this important topic.

However, despite the low percentage of respondents with personal experiences regarding Medicaid, it is quite obvious that these experiences - or the lack thereof - correlated with the respondents' attitudes and behavioral intentions to provide care for Medicaid patients. In consideration of these findings, it might be worthwhile to also reflect on the importance of a whole file review during the admission process. 
Table 5. Professional attitudes and behavior concerning Medicaid patients of respondents with different demographic or background characteristics

\begin{tabular}{|c|c|c|c|c|c|c|}
\hline & \multicolumn{2}{|c|}{ Gender } & \multicolumn{2}{|c|}{ White vs. Non-White } & \multicolumn{2}{|c|}{$\begin{array}{l}\text { Socioeconomic } \\
\text { Background }\end{array}$} \\
\hline & Male & Female & White & Non-White & Low & High \\
\hline \multicolumn{7}{|l|}{ Personal Experiences } \\
\hline $\begin{array}{l}\text { How much did you know about Medicaid } \\
\text { before you came to dental school? }\end{array}$ & 1.80 & $1.98^{+}$ & 1.88 & 1.86 & 1.95 & 1.82 \\
\hline $\begin{array}{l}\text { How much experience did you have with } \\
\text { Medicaid before dental school? } ?^{2}\end{array}$ & 1.48 & $1.64^{+}$ & 1.56 & 1.58 & 1.72 & $1.38^{* * *}$ \\
\hline \multicolumn{7}{|l|}{ Professional Attitudes } \\
\hline \multicolumn{7}{|l|}{ How confident are you when you . . . } \\
\hline $\begin{array}{l}\text { treat patients on Medicaid? }{ }^{3} \\
\text { answer questions about Medicaid? }\end{array}$ & $\begin{array}{l}3.69 \\
2.65\end{array}$ & $\begin{array}{l}3.63 \\
2.75\end{array}$ & $\begin{array}{l}3.56 \\
2.49\end{array}$ & $\begin{array}{l}3.81 \\
2.86^{*}\end{array}$ & $\begin{array}{l}3.77 \\
2.65\end{array}$ & $\begin{array}{l}3.53 \\
2.57\end{array}$ \\
\hline $\begin{array}{l}\text { How much do you enjoy working with } \\
\text { patients on Medicaid? }{ }^{4}\end{array}$ & 3.13 & $3.44^{* *}$ & 3.29 & 3.38 & 3.40 & $3.15^{*}$ \\
\hline \multicolumn{7}{|l|}{ Professional Behavior } \\
\hline $\begin{array}{l}\text { How likely are you to treat patients on } \\
\text { Medicaid? }\end{array}$ & 2.41 & $3.17^{* * *}$ & 2.71 & $3.15^{* *}$ & 2.85 & 2.74 \\
\hline $\begin{array}{l}\text { Would you accept only certain groups of } \\
\text { Medicaid patients? }\end{array}$ & $64 \%$ & $43 \% * * *$ & $54 \%$ & $49 \%$ & $51 \%$ & $57 \%{ }^{+}$ \\
\hline $\begin{array}{l}\text { Would you accept only a limited number } \\
\text { of Medicaid patients? }\end{array}$ & $80 \%$ & $66 \% * * *$ & $75 \%$ & $66 \%{ }^{+}$ & $67 \%$ & $79 \% * *$ \\
\hline \multicolumn{7}{|c|}{$\begin{array}{l}{ }^{1} \text { Answers ranged from } 1=\text { nothing to } 5=\text { very much. } \\
{ }^{2} \text { Answers ranged from } 1=\text { no experience at all to } 5=\text { =ery much. } \\
{ }^{3} \text { Answers ranged from } 1=\text { not at all to } 5=\text { completely confident. } \\
{ }^{4} \text { Answers ranged from } 1=\text { not at all to } 5=\text { very much. }\end{array}$} \\
\hline${ }^{+} p \leq 0.10 ;{ }^{*} p \leq 0.05 ;{ }^{* *} p<0.01 ;{ }^{* * *} p \leq 0.001$ & & & & & & \\
\hline
\end{tabular}

Such a review could consider whether students had prior personal or even professional/educational experiences (such as in community outreach or volunteer activities) with socioeconomically disadvantaged patients. Admitting increased numbers of students with such prior experiences could ultimately affect the way dental care is delivered to Medicaid patients.

Concerning professional experiences, the data showed that the large majority of respondents had experiences with treating patients on Medicaid. However, these experiences were not always positive, with 51 percent of dental students, 22 percent of dental hygiene students, and 74 percent of faculty members reporting that they had encountered problems before and with the severity of these problems ranging from minor to very extreme. These findings are important because they can be interpreted in the framework of the contact hypothesis. ${ }^{27}$ This theory addresses the question of how contact with out-group members affects prejudice and discrimination against these out-groups. In the case of this study, patients on Medicaid can be seen as out-group members with which only a minority of the respondents had prior interactions or experiences before coming to dental school. Coming in contact with patients on Medicaid in a clinical setting will therefore shape attitudes and behavioral intentions. The contact hypothesis predicts that the quality of the contact with these persons would affect the respondents' attitudes such as how much they enjoyed interacting with these patients. The data showed that the more severe the encountered problems were, the less the respondents enjoyed their interactions with Medicaid patients and the less likely they were to indicate that they wanted to treat these patients in the future. Not surprisingly, the data also showed that the more experiences they had, the less likely they were to intend to treat these patients in the future.

These findings should alert dental educators to the importance of ensuring that interactions between clinical faculty members and student providers about treating Medicaid patients are positive, as well as do- 
ing all they can to ensure that interactions between student providers and their Medicaid patients are positive. Communication breakdowns can easily occur when student providers are not well enough informed to give their Medicaid patients clear insights into, for example, the procedures that would be covered by Medicaid. Establishing rapport and maintaining a positive relationship assures patients that the provider has the expertise about Medicaid to optimally plan treatment and provide efficient care. Related to this consideration of the importance of giving students a comprehensive education about Medicaid is the finding that faculty members themselves lacked a high level of confidence when answering patient questions about Medicaid and reported that they were not likely to treat these patients in the future. In-service programs about Medicaid policies, especially in times of changes, would therefore be advisable.

Finally, in addition to the two objectives to explore the relationships between personal and professional experiences and attitudes and behavior concerning Medicaid, a first exploration of group differences in this context was also made. The finding that female providers as well as non-white providers had more positive attitudes towards Medicaid patients and were more likely to intend to treat these patients in the future than their colleagues deserves future exploration. While prior research ${ }^{11-18}$ had shown that non-white/minority providers were more likely to serve underserved minority patients, it might be worthwhile to explore the role of gender in this context as well in the context of care for other underserved populations such as children and patients with special health care needs.

This study has three limitations, which could be addressed in future studies. First, while the response rates of the dental and dental hygiene students were quite high (especially when considering that missing students might have been on external rotations and could thus not respond), the number of clinical faculty members was relatively small. A comparison of the gender and ethnicity/race percentages of the responding and nonresponding faculty members showed that these two groups did not differ on these characteristics. However, it is possible that the faculty members who responded were more interested in this topic than the nonrespondents. Such a potential bias would overestimate how positive the responses were. It is therefore important that future research explores in greater depth how clinical faculty members' attitudes and the way they role-model behavior when treating patients on Medicaid affect their students' attitudes and professional behavior. Second, while the students' intentions to treat patients on Medicaid in their future professional lives can be seen as the best predictor of their actual behavior, ${ }^{28,29}$ it would be worthwhile to conduct a follow-up survey with graduates of the same dental school or other programs to explore how their personal experiences prior to professional training and their professional experiences during their education actually affected their professional decision making on providing care for patients on Medicaid. The third limitation is concerned with the fact that data were collected in only one dental school. It would be interesting to see whether these findings held up in other educational settings.

The following conclusions can be drawn based on these findings. First, these dental and dental hygiene students' confidence in treating patients on Medicaid increased over the course of their education. However, their level of confidence in answering questions about Medicaid was still rather low even at the end of their educational program. Despite the fact that the dental students enjoyed treating these patients more in their final year of education than earlier, their intention to provide care for them decreased substantially from the first to the fourth years. Second, personal experiences with Medicaid prior to professional training positively affected these students' professional attitudes and behavioral intentions. Professional experiences with treating Medicaid patients are correlated with increased levels of confidence and enjoyment when treating them, but with a decrease in the behavioral intentions to actually treat them. Of special interest is the fact that the more severe problems with Medicaid patients were encountered, the less positive the respondents' attitudes were and the less likely they were to treat these patients. Finally, preliminary evidence was found that certain groups of participants in the study, namely female and non-white respondents, are more likely to intend to treat Medicaid patients compared with their colleagues.

\section{REFERENCES}

1. Hoffman ED Jr, Klees BS, Curtis CA. Overview of the Medicare and Medicaid programs. Health Care Financing Rev Statistical Suppl 2005;281:283-304.

2. U.S. Department of Health and Human Services, Centers for Medicare and Medicaid Services. At: www.cms.hhs. gov. Accessed: April 22, 2010.

3. ADA Survey Center. Just the facts: Medicaid. ADA News 2009;40(11):1. 
4. Oral health in America: a report of the surgeon general. Rockville, MD: U.S. Department of Health and Human Services, National Institute of Dental and Craniofacial Research, National Institutes of Health, 2000:7.

5. Medical News Today. Medicaid reimbursement for dental care too low, witnesses testify. Medical News Today, April 2, 2007. At: www.medicalnewstoday.com/printerfriendlynews.php?newsid=66614. Accessed: July 1, 2009.

6. Im JL, Phillips C, Lee J, Beane R. The North Carolina Medicaid program: participation and perceptions among practicing orthodontists. Am J Orthod Dentofacial Orthop 2007;132(2):144.e15-21.

7. Hughes RJ, Damiano PC, Kanellis MJ, Kuthy R, Slayton R. Dentists' participation and children's use of services in the Indiana dental Medicaid program and SCHIP: assessing the impact of increased fees and administrative changes. J Am Dent Assoc 2005;136(4):517-23.

8. Academy of General Dentistry. States that allow for direct Medicaid reimbursement of hygienists. AGD Transcript, April 2007. At: www.agd.org/support/articles/?PubID=4 7\&IssID=387\&ArtID=1477. Accessed: July 1, 2009.

9. Iben P, Kanellis MJ, Warren J. Appointment-keeping behavior of Medicaid-enrolled pediatric dental patients in eastern Iowa. Pediatr Dent 2000;22:325-9.

10. Utah's dentist workforce 2006: a study of workforce trends and capacity to provide service. Salt Lake City: Utah Medical Education Council, 2008.

11. Cantor JC, Miles E, Baker LC, Barker DC. Physician service to the underserved: implications for affirmative action in medical education. Inquiry 1996;33(2):167-80.

12. Komaromy M, Grumbach K, Drake M, Vranizan K, Lurie N, Keane D, Bindman AB. The role of black and Hispanic physicians in providing health care for underserved populations. New Engl J Med 1996;334(20):1305-10.

13. Moy E, Bartman BA. Physician race and care of minority and medically indigent patients. JAMA 1995;273(19):1515-20.

14. Porterfield DS, Konrad TR, Porter CQ, Leysieffer K, Martinez RM, Niska R, et al. Caring for the underserved: current practice of alumni of the National Health Service Corps. J Health Care Poor Underserved 2003;14(2): 256-71.

15. Rabinowitz H, Diamond JJ, Veloski JJ, Gayle JA. The impact of multiple predictors on generalist physicians' care of underserved populations. Am J Public Health 2000;90(8):1225-8.

16. Solomon ES, Williams CM, Sinkford JC. Practice location characteristics of black dentists in Texas. J Dent Educ 2001;65(6):571-4.
17. Stinson MH, Thurston NK. Racial matching among African American and Hispanic patients and physicians. J Hum Resources 2002;38(2):411-28.

18. Xu G, Veloski J, Hojat M, Politzer RM, Rabinowitz HK, Rattner SL. Factors influencing primary care physicians' choice to practice in medically underserved areas. Acad Med 1997;72(10):S109-S111.

19. Weaver RG, Haden NK, Valachovic RW. Annual ADEA survey of dental school seniors: 2002 graduating class. J Dent Educ 2002;66(12):1388-404.

20. Dao LP, Zwetchkenbaum S, Inglehart MR. General dentists and special needs patients: does dental education matter? J Dent Educ 2005;69(10):1107-15.

21. Rich JP III, Straffon L, Inglehart MR. General dentists and pediatric dental patients: the role of dental education. J Dent Educ 2006;70(12):1308-15.

22. Smith CS, Ester TV, Inglehart MR. Dental education and care for underserved patients: an analysis of students' intentions and alumni behavior. J Dent Educ 2006;70(4):398-408.

23. Brown BR, Inglehart MR. Orthodontists' and orthodontic residents' education in treating underserved patients: effects on professional attitudes and behavior. J Dent Educ 2009;73(5):550-62.

24. Garfinkle AJ, Richards PS, Inglehart MR. Providing care for underserved patients: periodontists' and periodontal residents' educational experiences, attitudes, and behavior. J Periodontol, forthcoming.

25. Kuthy RA, Heller KE, Riniker KJ, McQuistan MR, Qian F. Students' opinions about treating vulnerable populations immediately after completing community-based clinical experiences. J Dent Educ 2007;71(5):646-54.

26. Michigan Dental Association. Granholm orders cut to adult dental Medicaid, May 9, 2009. At: www.smilemichigan.com/NewsArticles/Archives/tabid/429/articleType/ ArticleView/articleId/335/Granholm-Orders-Cut-toAdult-Dental-Medicaid.aspx. Accessed: August 8, 2011.

27. Yehuda A. Contact hypothesis in ethnic relations. In: Weiner E, ed. The handbook of interethnic coexistence. New York: Continuum Publishing, 1998:162-81.

28. Ajzen I, Fishbein M. Attitudinal and normative variables as predictors of specific behaviors. J Pers Soc Psychol 1973;27:41-57.

29. Ajzen I, Fishbein M. The prediction of behavioral intentions in a choice situation. J Exp Soc Psychol 1969;5: 400-16. 